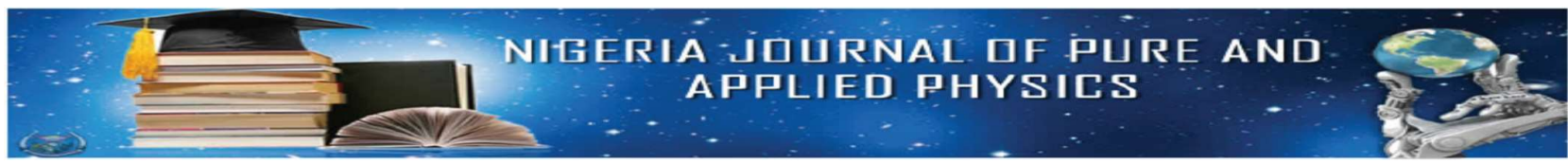

Nigeria Journal of Pure \& Applied Physics, Vol. 9, No. 1, pages 1-5, 2019

\title{
Effect of Phyisco-chemical Parameters on the Thermal Diffusivity and Soil Heat Flux over Ayadi, Ondo State, Nigeria
}

\author{
K. D. Adedayo ${ }^{\dagger}$ \\ Department of Physics, The Federal University of Technology, Akure, Nigeria \\ †Corresponding Author’s Email: kbadedayo@yahoo.com; kdadedayo@futa.edu.ng
}

\begin{abstract}
This study assesses the effect of some soil physical properties on the thermal diffusivity and soil heat flux over Ayadi in Ondo State, Nigeria. Physical properties of the soil at different depths were determined using laboratory techniques. In-situ measurement of air temperature and surface soil temperature were carried out. The phase lag method was used to determine the thermal diffusivity of the soil, while the subsoil heat flux was determined from values obtained for the thermal diffusivity. The result showed that the subsoil heat flux values during the dry season ranged between 0.58 and $52.84 \mathrm{~W} / \mathrm{m}^{2}$, while that of the wet season ranged between -0.77 and $98.50 \mathrm{~W} / \mathrm{m}^{2}$. The average thermal diffusivity values at the different depths had values between $0.74 \times 10^{-7}$ and $238.7 \times 10^{-7} \mathrm{~m}^{2} / \mathrm{s}$ for the dry season, while the wet season had a range of $1.97 \times 10^{-7}$ to $238.7 \times 10^{-7} \mathrm{~m}^{2} / \mathrm{s}$.
\end{abstract}

Keywords: soil moisture content, air temperature, soil temperature, soil heat flux, thermal diffusivity.

\section{INTRODUCTION}

The exchange of heat in the soil is very essential for the redistribution of moisture and nutrients in the soil. This exchange originates from the net solar radiation received at the earth surface which is absorbed in the ground in the form of soil heat flux. Soil heat flux is the energy received by the soil to heat it per unit of surface and time. Soil heat flux, together with sensible heat flux and latent heat flux are important in atmospheric physics because they are principally responsible for the re-allocation of energy across the earth surface [1]. The significance of surface energy balance extends towards various fields of application and it has been explored by several researchers $[2-6]$. The effects of soil heat flux on chemical and biological processes are conspicuous. Soil heat flux affects process by which water is transferred from the land to the atmosphere by evaporation from the soil and other surfaces and by transpiration from plants [7].

Thermal properties of soils are a component of soil physics that has found important uses in climatology, engineering and agriculture. Soil temperature is an important factor for plant growth like air, water and nutrients. The temperature of the soil can affect plant growths directly or indirectly by influencing moisture, aeration, structure, microbial and enzyme activities, organic matter decomposition, nutrient availability and other soil chemical reactions. Different crops adapt to specific temperatures. The movement of heat in the soil can be defined in terms of the thermal conductivity and diffusivity. Thermal diffusivity measures the rate at which heat is transferred from the hot to the cold side. It is defined as thermal conductivity divided by density and specific heat capacity [8].

Several factors can influence the thermal diffusivity and soil heat flux, among which are soil moisture content, soil temperature, vegetation cover, air temperature, soil texture and porosity. This study aims at assessing the impact of all these factors on the thermal diffusivity and soil heat flux over Ayadi, an agrarian community in Irele Local Government Area of Ondo State, Nigeria. Ayadi community falls between the bitumen sand belt of Nigeria. The geological formation of the area is the Precambrian basement complex rocks overlaid by the Eastern Dahomey basin. The area is located within the tropical rain forest and woodland belt of Nigeria thus, having a humid climate [9]. Crops commonly cultivated in the region include yam, okro, cassava, etc.

\section{MATERIALS AND METHODS}

A Davis Vantage Pro Weather Station equipped with data logger and tiny sensors from the Federal University of Technology Akure, installed at the experiment sites were used to acquire daily soil temperature data at depths 30, 40 and $50 \mathrm{~cm}$. The device consists of a solar panel, alternative battery source, and the wireless console which serve as the receiver from the integrated sensor suite (ISS). The ISS houses the temperature, pressure, relative humidity, and radiation shield sensors. The sensor interface module (SIM) transmits the measured values of the atmospheric parameters to the data logger. In-situ measurements of air temperature for $1 \mathrm{~m}$ above the soil surface were taken during the dry and rainy months. The choice of soil depths was due to the fact that most cereal crops cultivated at these locations have roots densities at these depths at their reproductive stage. 


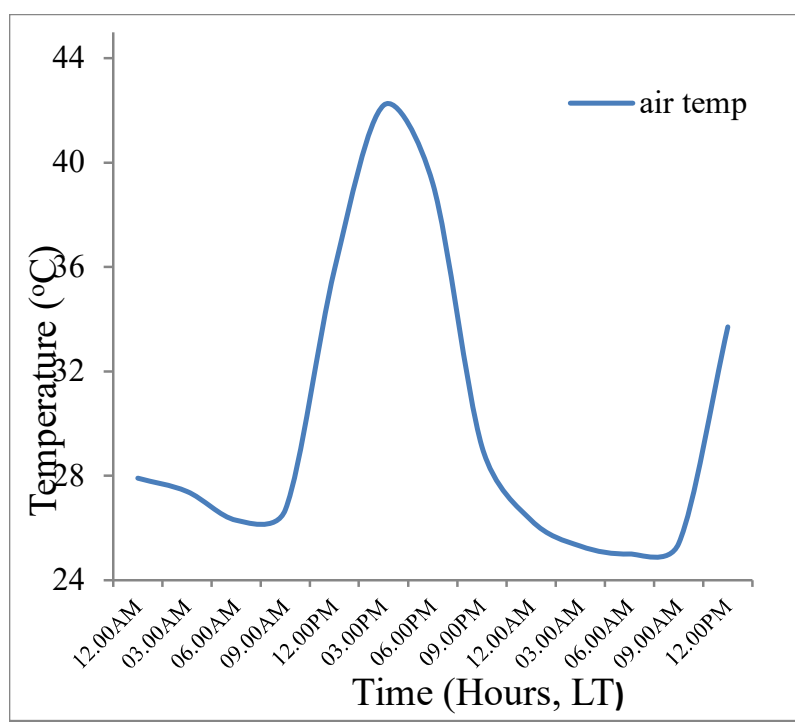

Fig. 1. Diurnal variation of air temperature at Ayadi, Irele L.G.A. during the dry season.

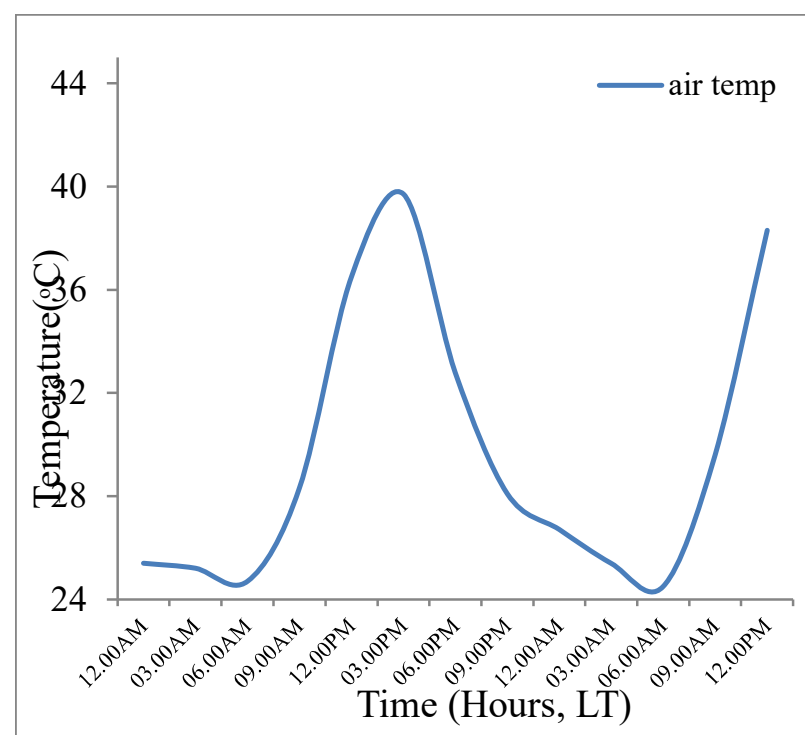

Fig. 2. Diurnal variation of air temperature at Ayadi, Irele L.G.A. during the wet season.

The measuring assembly is composed of different sensors that measure moisture content and temperature of the soil as well as the air temperature. The sensors were placed at 30 , 40 and $50 \mathrm{~cm}$ depths in the soil. The air temperature and soil temperature at the sites were measured at 3-hour intervals. Other physico-chemical parameters of the soil such as bulk density, specific heat capacity, porosity and moisture content were determined using laboratory methods. The calorimetric method was used to determine the specific heat capacity of the soil. The experimental research was carried during
March to April, 2012 for the dry season, and at mid June, 2012 for the wet season.

\section{Thermal Diffusivity of the Soil}

The thermal diffusivity of the soil was determined using the phase lag method. The phase lag between the thermal waves at two depths was used. The thermal diffusivity, D, of the soil was determined using the equation [10]
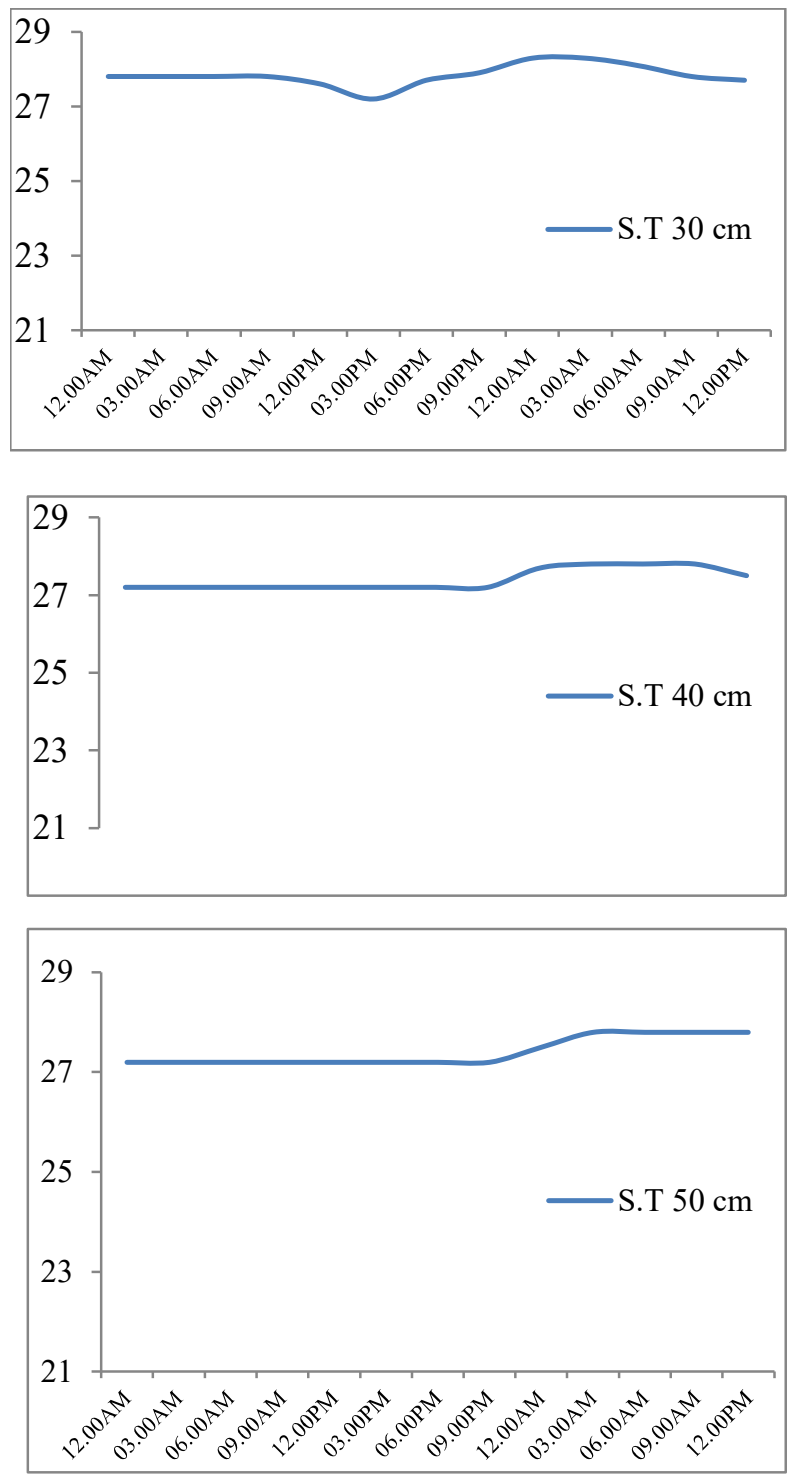

Fig. 3. Diurnal variation of soil temperature at Ayadi, Irele L. G. A. during the dry season.

$$
\mathrm{D}=\frac{\tau}{4 \pi}\left[\frac{Z_{2}-Z_{1}}{t_{2}-t_{1}}\right]
$$



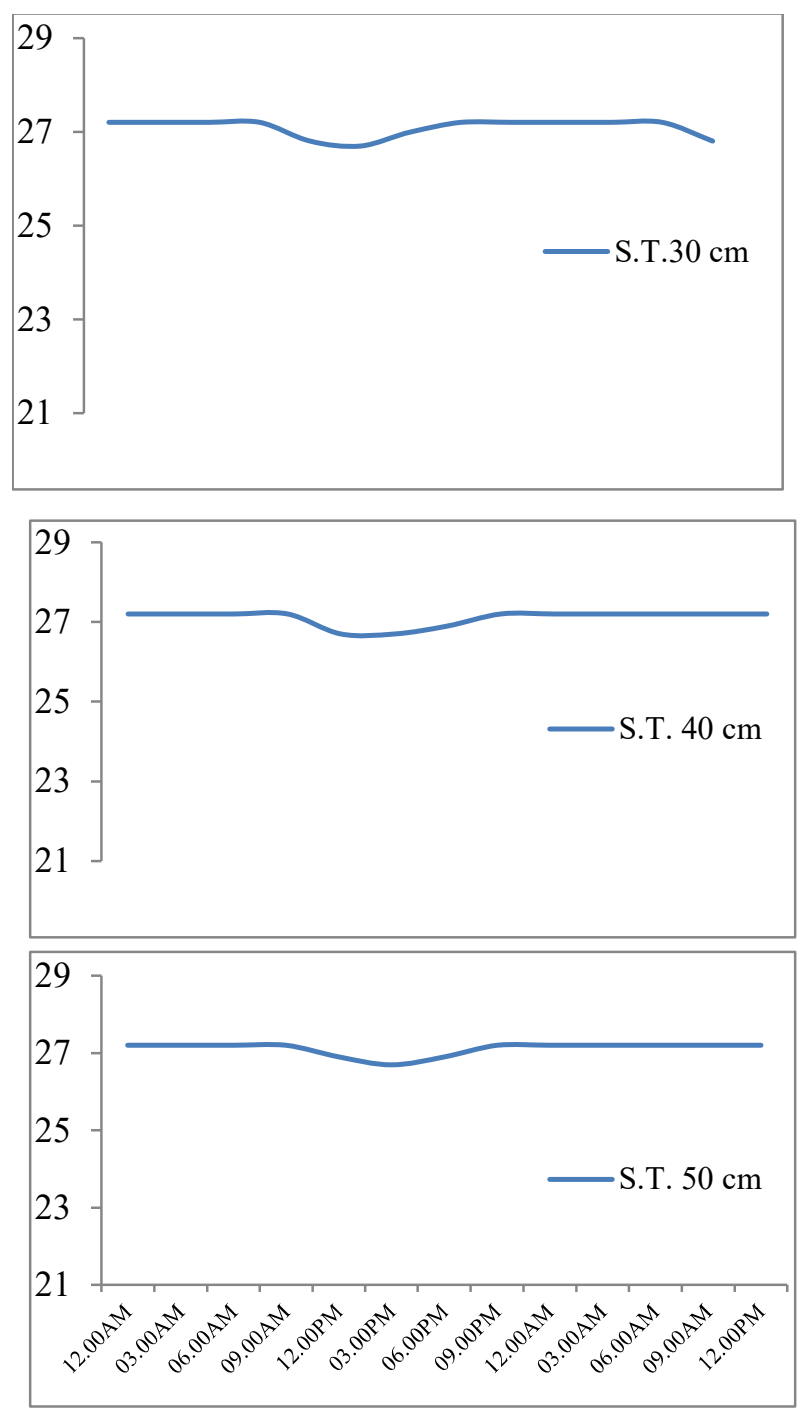

Fig. 4. Diurnal variation of soil temperature at Ayadi, Irele L. G. A. during the dry season.

where, $\tau$ is the period of fundamental cycle ( 24 hours), $Z_{2}$ and $Z_{1}$ are soil depths while $t_{2}$ and $t_{1}$ are the time taken for the amplitude of the temperature through $Z_{2}$ and $Z_{1}$ to get to its maximum or minimum values, $t_{1}(\mathrm{~s})$ and $t_{2}(\mathrm{~s})$ are the times (over a three hourly period) at which the temperature waves respectively reaches its maximum or minimum value at the two depths. The diurnal period of oscillation was 24 hours or $86400 \mathrm{~s}$.

\section{Soil Heat Flux}

The soil heat flux was determined using the equation [11]

$$
\mathrm{G}=-\mathrm{K}\left[\frac{T_{2}-T_{1}}{Z_{2}-Z_{1}}\right]
$$

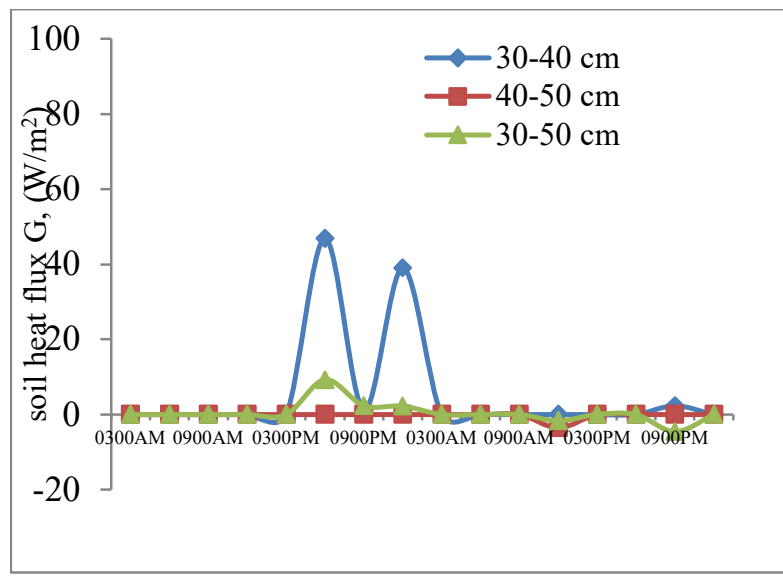

Fig. 5. Diurnal variation of soil heat flux at Ayadi, Irele L.G.A. during the dry season.

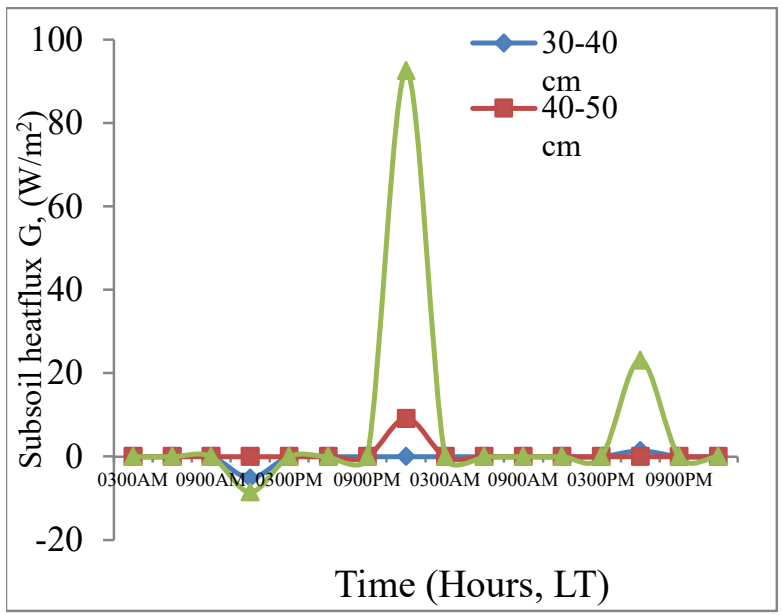

Fig. 6. Diurnal variation of soil heat flux at Ayadi, Irele L.G.A. during the wet season.

where, $T_{2}$ and $T_{1}$ are the maximum or minimum temperature at the two depths. $\mathrm{K}$ which is the thermal conductivity was obtained from the product of thermal diffusivity (D), soil bulk density $\rho_{b}$ and specific heat of soil $\left(\mathrm{C}_{\mathrm{P}}\right)$. Thus,

$$
\mathrm{K}=D \rho_{b} C_{p}
$$

\section{RESULTS AND DISCUSSION}

Figures 1 and 2 show the diurnal variation of air temperature at the study area during dry and wet season respectively. The average air temperature for the dry season was $42^{\circ} \mathrm{C}$ while that for the wet season was $39^{\circ} \mathrm{C}$. The air temperature attained the highest peak between 2 to $3 \mathrm{pm}$ in the dry and wet seasons. Figures 3 and 4 show the diurnal variation of soil temperature at the 30,40 and $50 \mathrm{~cm}$ depths 
Adedayo K. D: Effect of Phyisco-chemical Parameters on the Thermal Diffusivity ...

for the dry and wet seasons respectively. The average moisture content for the soil of the study area at the 30,40 and $50 \mathrm{~cm}$ depths were $9.33,8.48$ and $14.19 \%$ respectively. The bulk densities of the soils were $1.30,1.34$ and $1.40 \mathrm{~g} / \mathrm{cm}^{3}$ for the three depths while the porosities of the soils at different depths were $27.65,28.09$ and $30.80 \%$ respectively. The soil colour was dark brown in the $30 \mathrm{~cm}$ layer, indicating the presence of organic matter, reddish brown and dark red in the 40 and $50 \mathrm{~cm}$ layers respectively. The soil texture was sandy clay loam at the $30 \mathrm{~cm}$ layer, clay loam at the $40 \mathrm{~cm}$ layer and clay at the $50 \mathrm{~cm}$ layer.

The results obtained showed that the soil temperature decreased with depth. This can be attributed to the fact that temperature functions are greatest at the surface than at the subsoil. Also, clay soils have low porosity; they do not have much pores and holes in them which make it difficult for the transfer of heat between clayey layers. Soil temperature of the surface layer varies more or less according to air temperature. For clay soils, the heat received from the surface soil is held within the soil for a long time thereby increasing the temperature at the surface.

The diurnal variations of the subsoil heat flux for the dry and wet seasons are as shown in Figures 5 and 6 respectively, while Figures 7 and 8 show the diurnal variation of the thermal diffusivity of soil of the study area during the dry and wet seasons respectively. The subsoil heat flux values during the dry season ranged between 0.58 and $52.84 \mathrm{~W} / \mathrm{m}^{2}$, while that of the wet season ranged between -0.77 and 98.50 $\mathrm{W} / \mathrm{m}^{2}$ suggesting that more heat flowed downward during the rainy season. The average diurnal temperature at $40 \mathrm{~cm}$ depth was constant during the dry season thus leading to a constant thermal distribution throughout the period. This was also observed for the thermal diffusivity of the soils. The soil at $30 \mathrm{~cm}$ depth had a seemingly constant temperature distribution which led to reduced thermal diffusivity and soil heat flux at these depths. The subsoil heat flux were higher in the wet season than the dry season. This aligns with the results reported by other researchers [5,12]. Increasing moisture content in the soil increases the specific heat of the soil thus leading to an increase in the soil heat flux. Vegetation cover is also a factor that can affect soil heat flux. The intensity of temperature decreases due to the inhibition of the incident solar radiation received at the vegetated surface which results in a decrease in the intensity of the soil heat flux [13].

In determining the thermal diffusivity of the soil, the phase-lag method was used because it gives a better determination under uncontrolled conditions. The average thermal diffusivity values at the different depths had values between $0.74 \times 10^{-7}$ and $238.7 \times 10^{-7} \mathrm{~m}^{2} / \mathrm{s}$ for the dry season, while the wet season had a range of $1.97 \times 10^{-7}$ to $238.7 \times$ $10^{-7} \mathrm{~m}^{2} / \mathrm{s}$. The thermal diffusivity of the soil varied more during the wet season compared to the dry season. The continuous variation of the thermal diffusivity as seen in the wet season was as a result of the temperature fluctuations

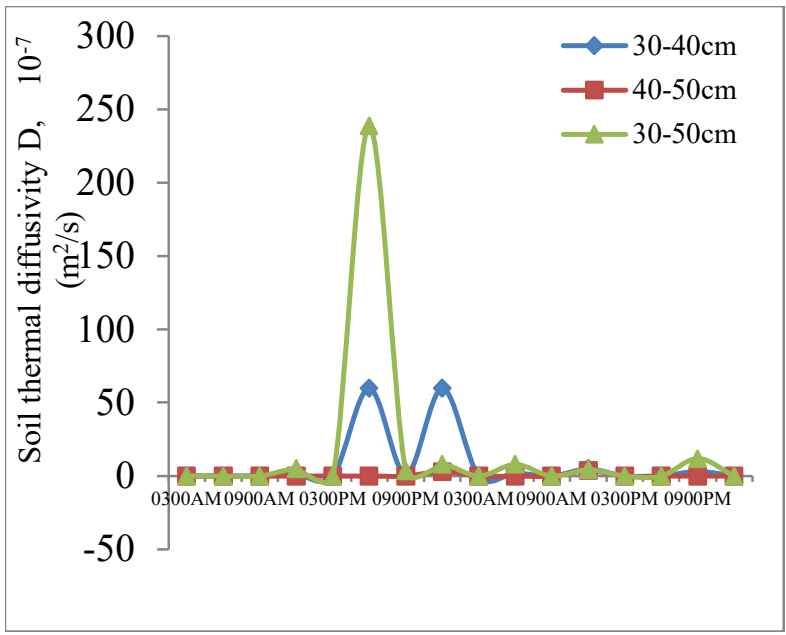

Fig. 7. Diurnal variation of thermal diffusivity of soils at Ayadi, Irele L.G.A. during the dry season.

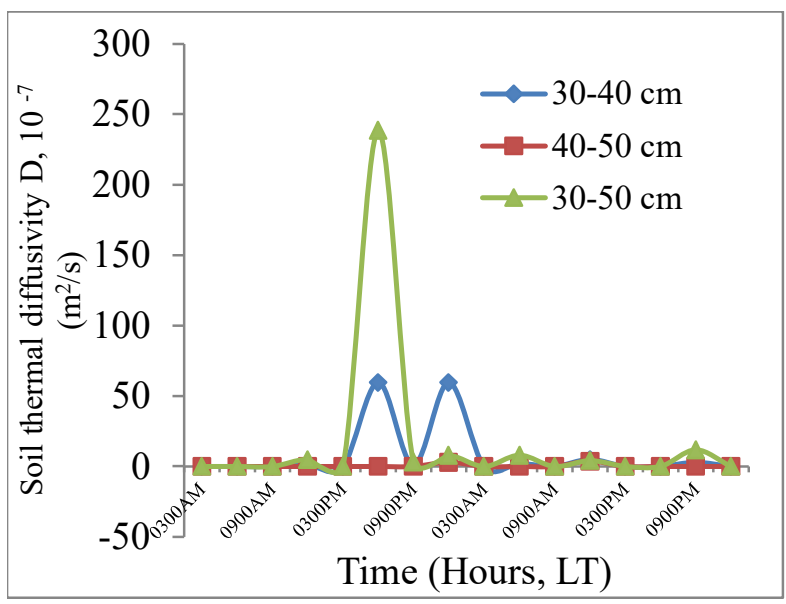

Fig. 8. Diurnal variation of thermal diffusivity of soils at Ayadi, Irele L.G.A. during the wet season.

during this period. Generally, the values obtained for the soil temperature, moisture content, soil heat flux and thermal diffusivity were within the acceptable limits suitable for the crops cultivated in these regions.

\section{Conclusion}

The effect of some physical properties of soil on the thermal diffusivity and soil heat flux over Ayadi, Irele Local Government Area of Ondo State have been determined. The result showed that to a large extent, the soil heat flux and thermal diffusivity are influenced by the moisture content of the soil, temperature of the soil as well as air temperature. The results showed high variability of the soil heat flux during the wet season compared to the dry season. The research work is recommended as a reference tool for understanding the possible changes that take place in the soil 
in relation to its temperature, thermal diffusivity and heat flux in the study area.

Generally, the results obtained for the physical and thermal properties of the soil of the study area show that the soils would support crop production, and will serve as a good medium for ground wave propagation.

\section{REFERENCES}

[1] Kakane, V. C. K., \& Agyei, E. K. (2006). Determination of surface fluxes using a Bowen ratio system. West Africa Journal of Applied Ecology, 9, 1-9.

[2] Guo, Y., \& Schuepp, P. H. (1994). On surface energy balance over the northern wetlands 1 . The effects of small-scale temperature and wetness heterogeneity. Journal of Geophysical Research, 99(D1), $1601-1612$. https://doi.org/10.1029/93JD01017

[3] Jegede, O. O., \& Lofstrom, P. (1997). Fluxes of sensible heat and momentum in the surface layer estimated from the profile measurements of wind and temperature at a tropical station. Atmósfera, 10(4), 213-223.

[4] Mauder, M., Jegede, O. O., Okogbue, E. C., Wimmer, F., \& Foken, T. (2007). Surface energy balance measurements at a tropical site in West Africa during the transition from dry to wet season. Theoretical and Applied Climatology, 89, 171-183. https://doi.org/10.1007/s00704-0060252-6

[5] Ogunjobi, K. O., Daramola, M. T., and Akinsanola, A. A. (2017) Estimation of surface energy fluxes from remotely sensed data. Spat. Inf. Res. https://doi.org/10.1007/s41324-0170149-8.
[6] Su, Z. (2002). The surface energy balance system (SEBS) for estimation of turbulent heat fluxes. Hydrology and Earth System Sciences, 6, 85-99.

[7] Allen, R. G., Pereira, L. S., Raes, D., \& Smith, M. (1998). Crop evapotranspiration-Guidelines for computing crop water requirements-FAO Irrigation and drainage paper 56. Fao, Rome, 300(9), D05109.

[8] Thermitus, M. A. (2010). New beam size correction for thermal diffusivity measurement with the flash method. In Gaal, Daniela D.; Gaal, peter S.(eds) Thermal Conductivity Conference/18th International Thermal Expansion Synposion. Lancaster PA: Destech Publications.

[9] Adeyemi, G. O. and Dairo, V. A. (2015) Subsurface models of A bitumen-Rich Area near Ode-Irele, Southwestern Nigeria. Journal of Applied Geology and Geophysics, 3(4): 13-19.

[10] Marshall T. J., Holmes J. W. (1988) Soil physics $2^{\text {nd }}$ ed. Cambridge University Press, New York

[11] Chacko, P. T., \& Renuka, G. (2002). Temperature mapping, thermal diffusivity and subsoil heat flux at Kariavattom of Kerala. Journal of Earth System Science, $\quad 111(1), \quad 79-85$. https://doi.org/10.1007/BF02702224

[12] Abu-Hamdeh, N. H. (2003) Thermal properties of soils as affected by density and water content. Biosystems Engineering. 86(1): 97-102 https://doi.org/10.1016/S1537-5110(03)00112-0

[13] Yang, Z.-L., Dia, Y., Dickinson, R. E., \& Shuttleworth, W. I. (1999). Sensitivity of ground heat flux to vegetation fraction and leaf area index. Journal of Geophysical Research, 104, 19505-19514.

https://doi.org/10.1029/1999JD900230 